\title{
Risk management: a proposal for communication strategies
}

\author{
Michele Fontana ${ }^{1}$, Mattia De Amicis ${ }^{1,}{ }^{\star}$, Matteo Rossetti ${ }^{2}$, Carolina Garcia ${ }^{1}$ \\ ${ }^{1}$ Università di Milano-Bicocca, Dipartimento di Scienze dell'Ambiente e del Territorio, Milano, Italy \\ ${ }^{2}$ Studio Architettura Rossetti, Milano, Italy
}

\author{
Article history \\ Received December 19, 2011; accepted February 9, 2012. \\ Subject classification: \\ Risk management, Communication campaign, Civil protection plan, Hydrogeological hazard, Risk awareness.
}

\begin{abstract}
Disasters related to natural hazards have increased in the last few decades. This increment makes it necessary to develop non-structural risk prevention and mitigation measures to improve people's safety. An effective non-structural measure that can improve the preparedness of the population is a locally adapted communication campaign that is focused on natural hazards. We have developed a hypothetical communication campaign for a specific area in the north of Italy, in which hydro-geological risk is of considerable importance. The content of the campaign is defined by the combination of the requirements of the law with the results of a survey conducted in the study area. The aim of the survey is to evaluate the level of risk perception among the residents, and their attitudes towards prevention activities. The operative procedure of the campaign is modeled on advertising strategies. The campaign is designed to reach each family, and it is aimed at affecting people's everyday life through a horizontal communication strategy that involves flyers, billboards, umbrellas and a website. The use of umbrellas as a medium for the campaign is the key. People mostly use umbrellas when it rains. Rain is linked with hydrogeological risk. As the content of the campaign is printed on the umbrellas, each time people use these umbrellas, they remember the campaign. The campaign is integrated into a broader communication program that includes meetings with stakeholders, activities in schools, and public conferences. The final goal is to foster the creation of a shared knowledge about risk in the whole population.
\end{abstract}

\section{Introduction}

Natural disasters have increased in Europe in the last decade [European Environmental Agency 2010]. Italy is no exception in this trend, and this increment makes it necessary to develop non-structural risk prevention and mitigation measures to improve people's safety. To this end, in the past few years, the Department of Environmental and Landscape Sciences (University of Milano-Bicocca), together with the Italian National Research Council (CNR), has carried out various studies in a specific area in the north of Italy. These studies include a comprehensive geological survey and a detailed hydrological study. Further- more, some activities of information and prevention have already been realized. Thus, the present study, which is focused on the communication to the general public, is part of a broader communication program, and it is realized in an area that is well known from a scientific point of view.

The central idea that guides our communication choices is that 'prevention is better than cure' [Bianco and Maggi 2000]. To create an extensive control network over the territory, our aim is to involve the whole population in the prevention activities. Prevention is a strategy based on simple everyday actions. People can have key roles in risk prevention, if they are aware of the hydrogeological nature of the territory in which they live. If each citizen starts to periodically check her/his neighborhood, she/he will be the first sentry against natural hazards. Thus, the goal is to reach as many citizens as possible.

\section{Territory and population}

This study is focused on the territory of the 'Comunità Montana di Valtellina di Tirano' (Mountain Consortium of Municipalities Valtellina di Tirano; hereafter MCMVT). The MCMVT is made up of twelve municipalities that are scattered over a $451.97 \mathrm{~km}^{2}$ area of the Italian Alps, in the Lombardy Region. The altitude goes from 373,000 to $2,902 \mathrm{~m}$ a.s.l. (Figure 1 ).

Starting from the last century, the population of the study area has sharply increased, and there are now 29,000 residents in the whole of the MCMVT. As a consequence of this larger population, over the last 60 years, new settlements have started to appear all along and down the valley. In time, these new villages have become more important and populous than the older ones, which is also due to internal migration from the mountains to the valley. With few people living on the mountainside, the traditional activities linked with life in the forests have disappeared. These activities were important actions in the management of the territory, and among other activities, they included the maintenance of the dry-stone walls 

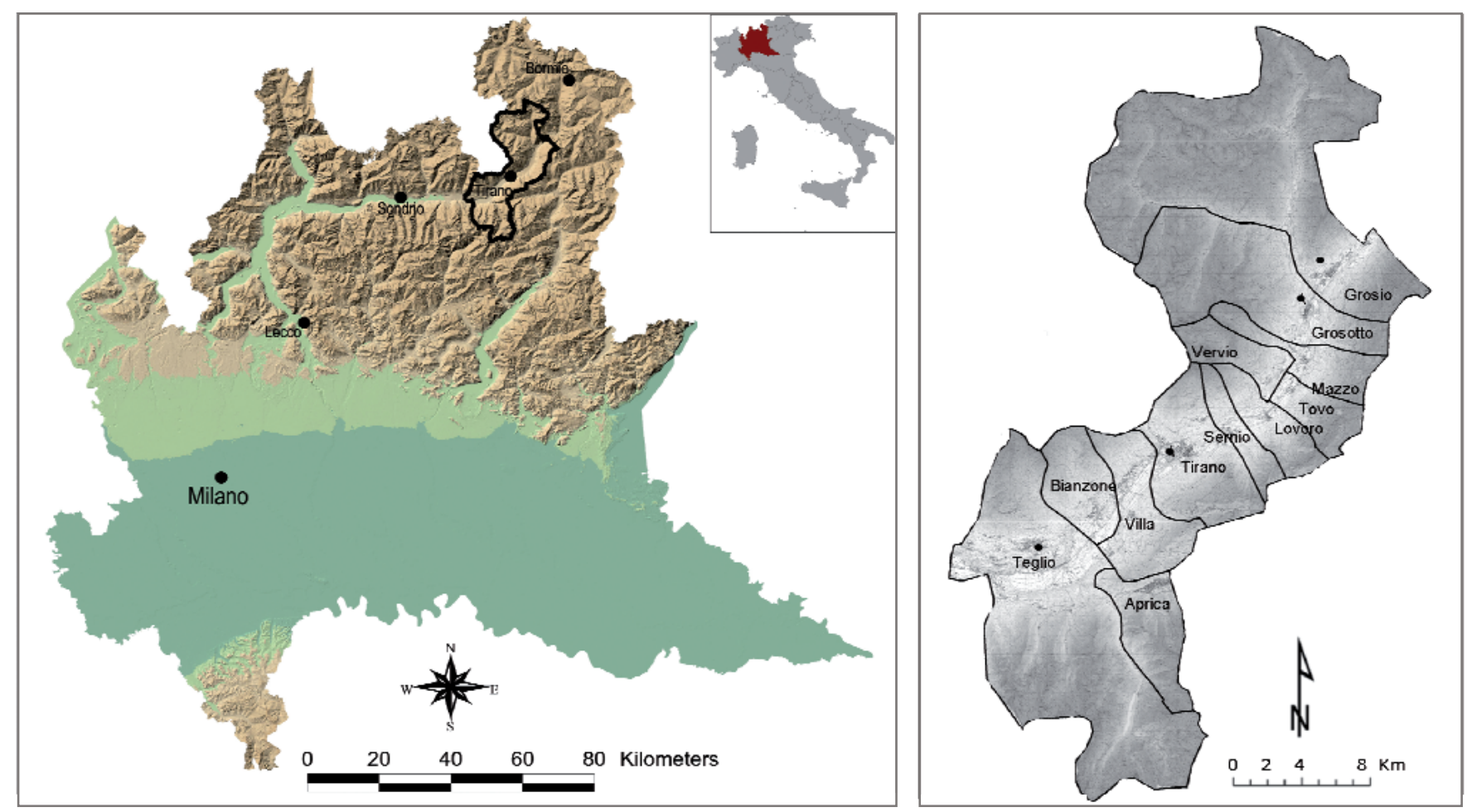

Figure 1. The study area.

and the gathering of the wood. Dry-stone walls slow down the velocity of run-off water, and during heavy rains, natural dams formed by water-transported twigs and branches used to form into streams.

Thus, the consequences of the changes in the demography have resulted in a loss of control over the territory, and a subsequent increase in the risk of flooding. Moreover, the hydrogeological regime of the MCMVT is no longer natural, because the rivers are used for hydroelectric purposes (as more people need more energy).

In conclusion, today the territory of the MCMVT is characterized by high hydrogeological risk due to its socioeconomic and geographical characteristics [Sterlacchini et al. 2008].

\section{Local civil protection plans}

The content of the communication campaign is defined by the combination of the requirements of law with the results of a survey that was conducted in the studied area. The law of the Lombardy Region ${ }^{1}$ describes what has to be done when speaking about natural hazard prevention. The law identifies four main subjects: preventive communication, training, emergency drill, and planning. The corner stone of the planning is the Civil Protection Local Plan (CPLP). Each municipality has its own CPLP that identifies the risks to which the territory is subjected, as well as the areas that might be affected by a specific risk. Also, the CPLP locates the safe zones in which people can take refuge during an emergency. Thus, the CPLP contains the information that the population has to know to be prepared for an emergency: where hazards might strike and where to go to be safe. From this point of view, preventive communication, the first subject identified by the law, can be thought of as the communication of the CPLP to the general public.

\section{The survey}

The population of the MCMVT was the subject of a survey carried out in person by one of the authors of this paper [Garcia 2011]. The aim of the survey was to evaluate the level of risk perception among the residents, and their attitude towards prevention activities. Risk perception is a key factor when planning a communication campaign. If the citizens are aware of the risks that exist on their territory, they will be receptive to a communication campaign focused on these risks. In contrast, if the citizens do not know about the risks, they will be indifferent to the same campaign, because the information will be considered outside of the citizens' sphere of interest [Lombardi 2005]. Surprisingly, the results of the survey showed that despite having good knowledge of previous flooding and mass movements, ${ }^{2}$ the population of the studied area has low levels of perceived risks and preparedness (Table 1).

However, the population also showed interest in being informed about natural hazards, mitigation activities, risk management and emergency procedures, as $67.3 \%$ of the respondents expressed willingness to learn how to be better prepared in the case of a future event. This includes learning about the appropriate mitigation activities that they can directly perform to be less vulnerable. Also, the results highlighted that the preferred sources of information are local authorities and not the 
Population with knowledge of previous flooding and mass movements

Table 1. Results of the survey on risk perception (adapted from Garcia [2011]).

scientific community. ${ }^{3}$ This indicates the need to work in collaboration with the local authorities to communicate scientific information, otherwise the same scientific information will not be willingly received by the general public [Gallavotti and Pistoni 2007, Bucchi 2008].

\section{Communication strategies}

The operative procedure of the campaign is modeled on advertising strategies, as the final goal of our campaign is to get close to the goal of a commercial campaign. Like an advertiser, we want to suggest to our target to do something [Packard 1958]. Of course, our aim is not linked to some commercial purpose, but to risk prevention. The center of our campaign is the idea of safety, and the suggestion that through the adoption of specific behaviors, it is possible to make the place in which one lives safer, both in everyday life and during an emergency.

It is important to note that we do not think that this campaign is self-sufficient, to create better risk perception, or even that this campaign will be sure to reach everyone. This campaign is only one of all of the initiatives that should be developed to create sensitivity in everyday life in a risk-exposed territory. Indeed, extensive work has already been done in the territory. Meetings with students and teachers have been arranged to discuss risk prevention in many of the schools of the MCMVT. ${ }^{4}$ Local authorities have met researchers of the Department of Environmental and Landscape Sciences and of the National Research Council, to understand how a CPLP is made and how to use it before and during an emergency. This activity has been carried out inside the Doctoral research project of one of the Authors, and the cost has been borne through the contribution of a European Community project, called Mountain Risk.

Now, we believe that it is important to try to reach the whole population, to foster the creation of a widespread awareness of risk, and this is the reason that lies behind the design of this hypothetical campaign.

The campaign is designed to reach each family and it is aimed at affecting people's everyday life through a horizontal communication strategy. The focus on everyday life is rooted in the impossibility of defining the exact moment in which an emergency might take place. Thus, although the law insists that preventive information has to continuously run all the time, it is clear that repeated excesses in risk communication can easily generate the "cry wolf" phenomenon, which would cancel out the effects of all of the effort. Several studies have shown that if the notice of an imminent disaster is not followed by the disaster itself, further communications will be received with increasing skepticism by the citizens [Anderson 1968, Baker 1984, Atwood and Major 1998]. Therefore, it is important to calibrate the communication, and to prefer initiatives that seek to change people's behavior by acting on their everyday lives. Communication that establishes artificial situations of emergency should be avoid, as they are destined to fade into nothingness, and they can also erode the general credibility in the source of the communication.

Combining the requirements of law with the results of the survey, we created four iconic-text symbols (Figure 2). On the one hand, these symbols draw attention to some aspect of the CPLP (where hazards can strike, and where to go to be safe). On the other hand, these symbols answer the citizens' desire that was highlighted by the survey: to know which activities they can directly perform to be less vulnerable. These symbols include:

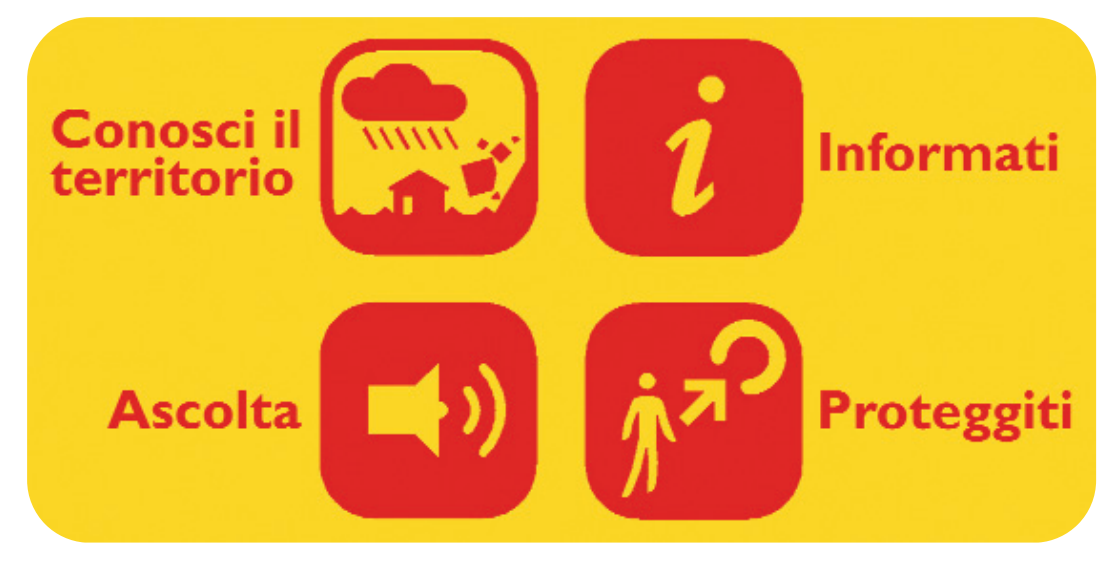

Figure 2. The four symbols of the campaign.

- The symbol of "Know the territory" (Figure 2, top left, "Conosci il territorio" in Italian). The aim of this symbol is to push the population to know their own territory. If a citizen knows that their house might be flooded by the river, then there are more chances not only that they will be ready to move away in time, but also that they will constantly check the river during (for example) heavy rain. 
- The symbol of "Inform yourself” (Figure 2, top right, "Informati" in Italian). The aim of this symbol is to suggest to people that they should also seek information by themselves. It is unrealistic to think that the Mayor of each Municipality will go house-to-house to explain how to reach the safe zones from each house. If the majority of the citizens become responsible for their own safety, the authorities can better deal with the extreme situations of an emergency (for example: older people who are not able to move). This symbol is the logical consequence of the previous symbol: to know your territory you have to have the necessary information.

- The symbol of "Listen" (Figure 2, bottom left, "Ascolta" in Italian). This symbol reminds the population that they will not be abandoned in the case of an emergency. The authorities will coordinate the rescue operations, keeping the population updated on the situation. As different Municipalities of the MCMVT can use different methods to communicate with the population, ${ }^{5}$ this symbol is not focused on a specific media.

- The symbol of "Protect yourself" (Figure 2, bottom right, "Proteggiti" in Italian). This symbol represents what should be the first thought of everyone during an emergency: to protect their own personal safety. Speaking of hydrogeological risk, this means to move away from exposed zones. To know which are the exposed zones is the goal of the first symbol. Thus, if you know the territory, you should be safe.

Each symbol is made up by text and an image, joined together as a single unit. In this way, the symbols are more understandable because the two parts, the text and the image, clarify one another [Calabrese 2007]. The linguistic choice of the text is oriented towards messages that promote citizens' direct participation, while avoiding negative messages or prohibitions, which are considered as little effective in establishing a dialogue [Barszczynska et al. 2006]. From a visual point of view, the shapes of the symbols are very different from shapes usually linked with emergency situations. Emergency situations are represented by triangles. The use of the square, with the rounded angles, is designed to support the ideas of solidity and safety [Kandinsky 1926], which are central to the campaign.

These four symbols are grouped together in a single picture that becomes the logo of the campaign. The campaign is composed of four phases (Figure 3). First, a flyer is sent to all of the 10,000 resident families. The flyer presents the logo and explains the meaning of each symbol. The flyer is sent from the MCMVT, an institution that, as the survey highlighted, is trusted by the population. After two weeks, an umbrella is sent to each of the families. The umbrella has the logo printed on the cloth. Then billboards are placed in each municipality that explain the specific meaning of each symbol according to the specific territory of that municipality (what kind of hydrogeological risk exists in that municipality; what is the communication strategy that the municipality will use in the case of an emergency; what are the locations of the safe zones in that municipality).

Parallel to the previous phases, a website is put online, and it will be possibly for this to be hosted within the website of the MCMVT, with the aim of assuring continuity to the campaign. The website contains all of the information that has been spread through the previous phases, and it represents a constant point of reference for the population, supplying both information and contact details to reach the authorities.

So, the campaign starts with an institutional communication (MCMVT - flyer), passes through a common object that becomes part of people's everyday life, and ends with a local institutional communication (municipality - billboards), finally staying on through the website.

The choice of the umbrella is not casual. The idea to use an object in the campaign is taken from guerrilla marketing campaigns. The effectiveness of this kind of strategy comes from the capability of the object to enter almost unnoticed into the everyday life of the target of the campaign. ${ }^{6}$ As hydrogeological hazards are mainly triggered by rain, we choose to use an umbrella. An umbrella is a common object that is used by everyone without regard for gender, age and culture. Therefore, an umbrella is an ideal object to reach a wide number of people. Moreover, an umbrella presents a wide surface that is available for printing information. In this way, every time a citizen takes this umbrella because it is raining, and opens it, they will see the logo. The logo should remind the person about the hydrogeological risks and the communication campaign. Even if some of the umbrellas get lost, we believe that just seeing a few of these umbrellas around on a rainy day will trigger the memory of the campaign. Thus, through this dynamic, it should be possible to transform a simple daily gesture into an action of prevention, and to contribute to the creation of a common and shared awareness of the territory and its risks.

Therefore, the idea is not to generate alarm in the people with sudden announcements of imminent disasters, but to help citizens to recognize that in their particular territory specific risks exist on an everyday basis, and that with risk awareness, that risk can be greatly reduced.

The total cost of this campaign is, more or less, 70,000 euros, subdivide in this way: 45,000 euros for the umbrellas (for 10,000 inhabitants), 2,000 euros for the brochure and leaflet, and 3,000 euros for other costs. It is also clear that this campaign can be realized only with the contri- 


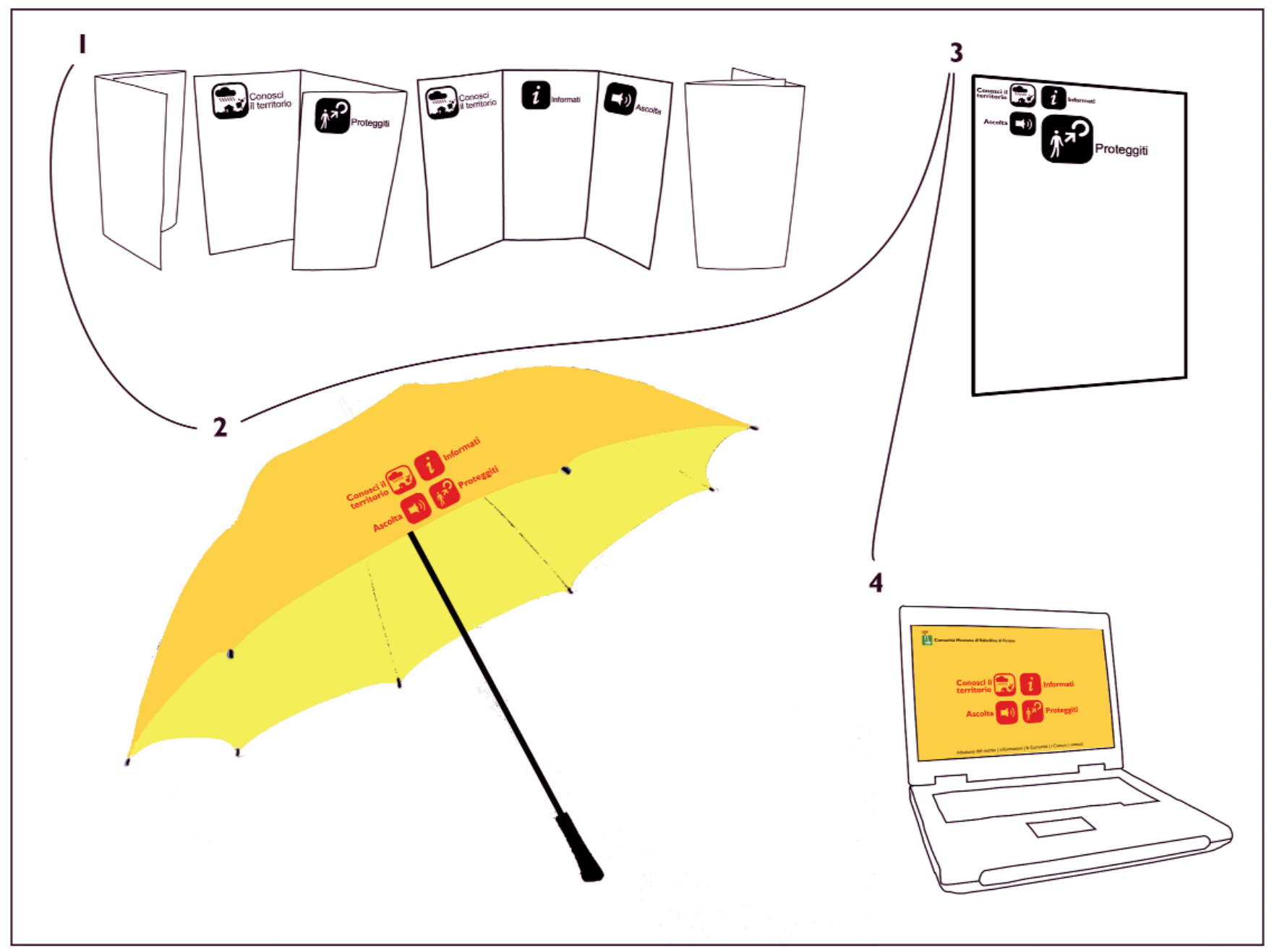

Figure 3. The phases of the campaign.

butions of sponsors. For this reason two of the main banks in the territory, Banca Popolare di Sondrio and Credito Valtellinese, have been contacted.

\section{Conclusion}

This study puts together two issues: (a) The preventive communication that has to be carried out according to law; and (b) the people's desire to know how to directly reduce the risk in their territory. In doing this, the campaign relies on studies that have been carried out by researchers over the past few years, even if it could be argued that in the campaign the scientific information becomes closer to an advertisement than to a scientific paper.

However, there is little value in producing high quality research if the results are not put into practice. With this campaign, we have tried to explore a way to build communication between scientists and residents. Scientists know the natural hazards and how to reduce the risks linked with them, but it is the citizens who live in the territory. Thus, it is important to create communication between scientists and the population. This communication has to go through the local authorities, as they are more trusted by the population than scientists. This preference should push the sci- entific community to ask itself what went wrong. Why do lay people not trust scientists today? We do not have the answer to this question at present, but we do hope that working together with the authorities and this active contribution to the safety of the population through taking science to the society will help to improve scientists' credibility in time.

The final goal of this campaign is to foster the creation of shared knowledge about the risks in the whole population. Hydrogeological risk is caused also by the use that people make of their territory. For reasons that are partially related to industrialization, many inhabitants of the MCMVT have stopped to live in mutual relations with their territory. The traditional practices that were linked to the local culture have been abandoned. Today, many residents of the MCMVT live close to the mountains as if they live in a town on the plain. So, the challenge we face is to contribute to the creation (or re-creation) of their sensitivity to the specific environment that characterizes the MCMVT. If we succeed in this, every citizen can become a node of an extended monitoring network. Due to their knowledge of the territory and to their behavior during both everyday life and in emergencies, they will surely be able to live in a safer territory. 


\section{Notes}

1. Law reference: Regione Lombardia, Direttiva Regionale per la Pianificazione di emergenza degli Enti locali (L.R. 16/2004 - art. 7, comma 11, approvata con D.G.R. n.VIII/ 4732 del 16 maggio 2007).

2. Flooding and mass movements are the most significant natural hazards in the MCMVT.

3. When asked about which source should provide information on natural hazards, $74.8 \%$ of the respondents said 'the Municipality', while only $8.2 \%$ of the respondents said 'the scientific community' [Garcia 2011].

4. These activities were coordinated by Lisa Garbellini (IREALP).

5. Some of the possible methods are: cell phone SMS messaging, the internet, television, and loud-speakers on police cars. Of course, one method does not exclude another. It is also possible that in time new methods will arise.

6. More information about this can be found at: http:/ / www.guerrigliamarketing.it/;

http://www.advertnews.com/category/ad-agency/.

\section{References}

Anderson, J.W. (1968). Cultural adaptation to threatened disasters, Hum. Organiz., 27, 298-307.

Atwood, L.E., and A.M. Major (1998). Exploring the 'cry wolf' hypothesis, Internatl. J. Mass Emergen. Disast., 16, 279-302.

Baker, J. (1984). Public Response to Hurricane Probability Forecasts, National Weather Service, Washington, D.C., 35 pp.

Barszczynska, M., R. Bogdanska-Warmuz, R. Konieczny, P. Madej and M. Siudak (2006). In Time for the Flood - A Methodological Guide to Local Flood Warning Systems, Institute of Meteorology and Water Management, Poland, 94 pp.

Bianco, G., and M. Maggi (2000). Prevenire è meglio che curare? Prime analisi propedeutiche per un'indagine su scala regionale su calamità naturali e prevenzione, Working paper n. 130, Istituto Ricerche EconomicoSociali del Piemonte, Italy, $80 \mathrm{pp}$.

Bucchi, M. (2008). Dal deficit al dialogo, dal dialogo alla partecipazione - e poi? Modelli di interazione fra scienza e pubblico, Rassegna Italiana di Sociologia, 49 (3), 377-402.

Calabrese, S. (2007). Retorica del linguaggio pubblicitario, Bologna, Archetipolibri, 184 pp.

European Environment Agency (2010). Mapping the impacts of natural hazards and technological accidents in Europe. An overview of the last decade, Publications Office of the European Union, Copenhagen, 186 pp.

Gallavotti, B., and S. Pistoni (2007). La comunicazione Istituzionale della Scienza: Come Evitare la Deriva Autoreferenziale, Analysis, 4, 20-23.

Garcia, C. (2011). Mountain risk management: integrated people-centered early-warning system as a risk reduction strategy, northern Italy, PhD thesis, Supervisors: Mattia di Amicis, Simone Sterlacchini, Department of Environmental and Landscape Sciences, University of Milano-Bicocca, Italy, 150 pp.
Kandinsky, W. (1926). Uber das Geistige in der Kunst, Langen, Munchen, Bauhaus Bucher; consulted edition: Punto linea e superficie, Milano, Adelphi, 1968.

Lombardi, M. (2005). Comunicare nell’emergenza, Milano, Vita e Pensiero, $160 \mathrm{pp}$.

Packard, V. (1958). I persuasori occulti, Torino, Einaudi, 286 pp.

Sterlacchini, S., M. De Amicis, S. Frigerio, S. Sironi and I. Poretti (2008). Metodologia per l'analisi della pericolosità da inondazione, CNR - IDPA, Italy, 135 pp.
^Corresponding author: Mattia De Amicis, Università di Milano-Bicocca, Dipartimento di Scienze dell'Ambiente e del Territorio, Milano, Italy; email: mattia.deamicis@unimib.it.

(C) 2012 by the Istituto Nazionale di Geofisica e Vulcanologia. All rights reserved. 